\title{
FRACTAL ANALYSIS FOR AKAMURA MOUNDED TOMB AND LOCATION ESTIMATE OF YAMATAI COUNTRY
}

\author{
Susumu Ogawa ${ }^{1, *}$, Yukiya Taniguchi ${ }^{2}$ \\ ${ }^{1}$ Institute of Spatial Technology, Toyo, Koto-ku, Tokyo, Japan - ogawa_susumu_phd@ @ahoo.co.jp
${ }^{2}$ Institute of Industrial Science, University of Tokyo, Komaba, Meguro-ku, Tokyo, Japan - taniguchi-yukiya312@g.ecc.u-tokyo.ac.jp
}

Commission IV, WG IV/3

KEY WORDS: Ancient mound, Dating, Morphology, Sanguozhi, Spatial analysis, Spatial distribution, Watershed

\begin{abstract}
:
In 2018, the ancient tomb was discovered in Tagawa, Fukuoka. The sizes of the tomb were measured by UAV. The length is $443 \mathrm{~m}$, the diameter is $152 \mathrm{~m}$, and the height is $33 \mathrm{~m}$ : the second biggest mound in Japan. Chinese history book, Sanguozhi (Chen, 280) reads Yamatai country occupied 27 countries in Japan in the $3^{\text {rd }}$ century by the queen Himiko. The location of Yamatai was $840 \mathrm{~km}$ south from Soul with 70000 families, and the size of Himiko's tomb was $150 \mathrm{~m}$ diameters. The locations of Yamatai country and Himiko's tomb are still unknown. From Sanguozhi, the optimum location was estimated with the direction, the distance and family numbers. Family numbers were estimated from the river watershed areas. Kyushu islands have 28 big rivers, corresponding to 28 countries described in Sanguozhi. Each river corresponded to each country, and their family number was estimated by $2.5 \%$ of the watershed area with family number / 10 a. Finally, the Chikugo river watershed was a candidate of Yamatai country. Moreover, two kinds of tombs became candidates of Himiko's tomb.
\end{abstract}

\section{INTRODUCTION}

In the $3^{\text {rd }}$ century in Japan, 30 countries were recognized by China. Yamatai country was a representative of them. However, the location of this country and Himiko's tomb was still uncertain. The fundamental reasons were Sanguozhi description (Chen, 280): the location of 8 countries was shown by the directions, the distances, and family numbers. Most of historians judged the location of each country by only the directions and distances. Nobody used the family numbers for the location of each country. If the location of each country was calculated by three parameters: the directions, the distances and the family numbers, the result should be changed. The family numbers can be derived from the river watershed areas: the constant ratios of rice fields exist each river watershed and each family needs ten a of rice field. Therefore, the river watershed corresponded to a country. For the past 100 years, two areas were discussed between two major universities: Kyushu island and Kinki; the former was selected from the directions in Sanguozhi by University of Tokyo while the latter was selected from the distances in it by Kyoto University. RMS, normalized Root-Mean-Square error, is the indicator of optimization for Yamatai country location. The optimum location was obtained for Yamatai country with RMS. On the other hand, in 2018, one big ancient tomb was discovered in Akamura, Tagawa, Fukuoka: the field survey by UAV showed the length is $443 \mathrm{~m}$, the diameter is $152 \mathrm{~m}$, and the height is $33 \mathrm{~m}$ : the second biggest keyhole-typed mound in Japan. The diameter of Himiko's tomb was described as $150 \mathrm{~m}$ in Sanguozhi, corresponding to this tomb. Moreover, 30 mounded tombs exist around Akamura mounded tomb, which are keyhole and round tombs and their shapes relate with the construction years. The regression equations were obtained for the construction year estimate. These big mounded tombs suggest the relationship with the Japanese emperors, This paper solved uncertain Japanese history in the third century, Yamatai and the queen Himiko locations by the optimization with three parameters, directions, distances, and family numbers each country of Yamatai described in Sanguozhi. The results were reasonable and should be validated by future archaeological research. The used model is very simple.

\footnotetext{
*Corresponding author
}

\section{METHODS}

\subsection{D images}

The 3D images for the tomb of Akamura were measured by UAV. UAV was Phantom 4 Professional with $4 \mathrm{~K}$ camera. Pictures were synthesized to 3D orthogonal images with PhotoScan. The orthogonal image was processed to a monochromic silhouette and the edge image with Photoshop. Fractal analysis was carried out for these horizontal images and DEM. Fractal dimension $D$ is defined as

$$
D=\log N / \log R
$$

where $N$ is the number of pixels and $R$ is the size of the images (Mandelbrot, 1983).

The shape factor $\phi$ is defined as

$$
\phi=L^{2} / S
$$

where $L$ is the maximum length of images and $S$ is the area of the images.

Topographical rules were also applied for horizontal images and cross sections of DEM (Appendix A).

\subsection{Dating the ancient tombs}

Ueda (1969) showed some important results for the keyhole tombs: The keyhole tomb dimensions, the diameter a, the bottom side $\mathrm{b}$, and the length $\mathrm{c}$, have positive correlation between $\mathrm{b} / \mathrm{c}$ and $\mathrm{b} / \mathrm{a}$ and depend on the construction year; three characteristic sizes showed integer ratios and categorized three shape types (Appendix B).

By the list of the ancient keyhole and round tombs, two regression expressions were obtained for the dating of discovered tombs. The types of the tombs were three: keyhole, round, and ellipse shapes and the dates each was estimated to be built. The keyhole type has three sizes, the diameter a, the base $b$, and the length $c$, which are correlated with the date of the construction (Ueda, 1969). The round type has two sizes, the diameter $\mathrm{D}$ and the height $\mathrm{H}$, which are correlated with the dates of the construction. Ellipse tombs were very few and excepted. 

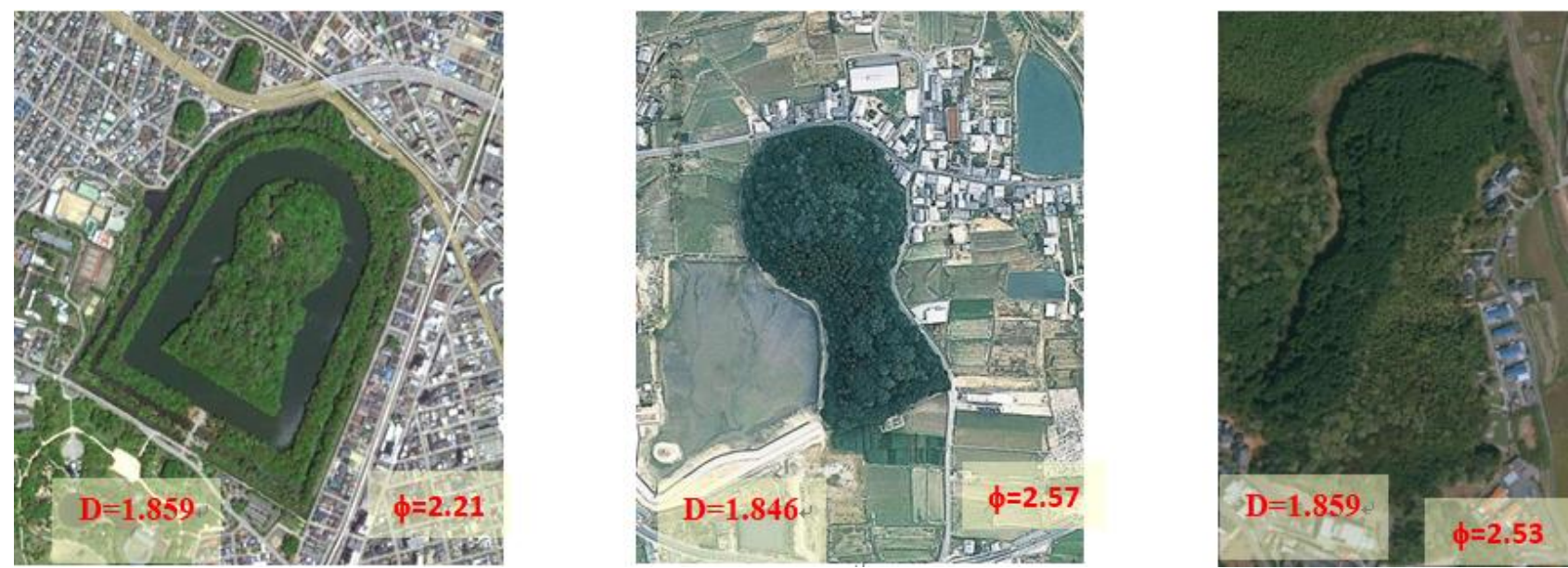

Figure 1. Three tombs: Nintoku, Hashihaka and Akamura

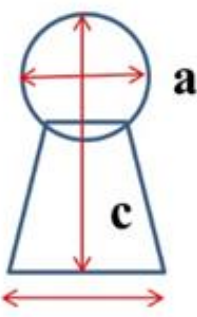

a

D

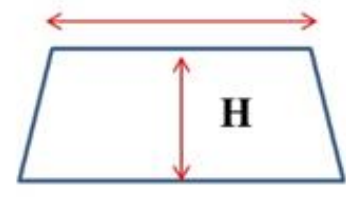

b

Figure 2. Keyhole and round tomb sizes

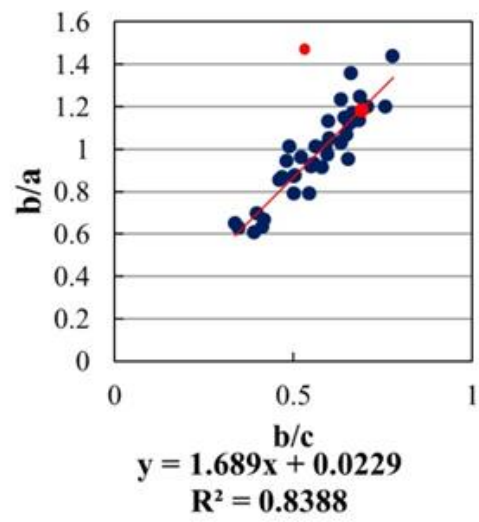

Figure 3. Keyhole tomb size correlation

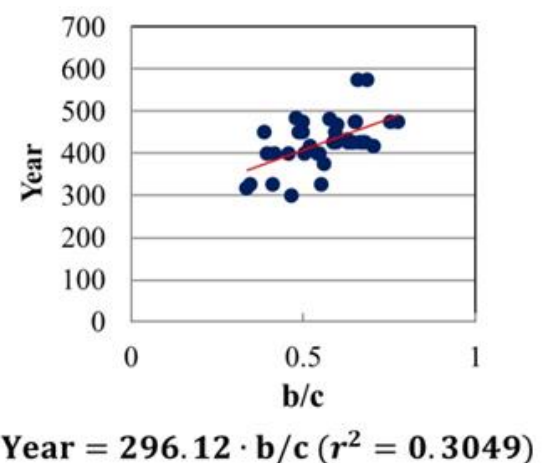

Figure 4. Keyhole tomb age estimate

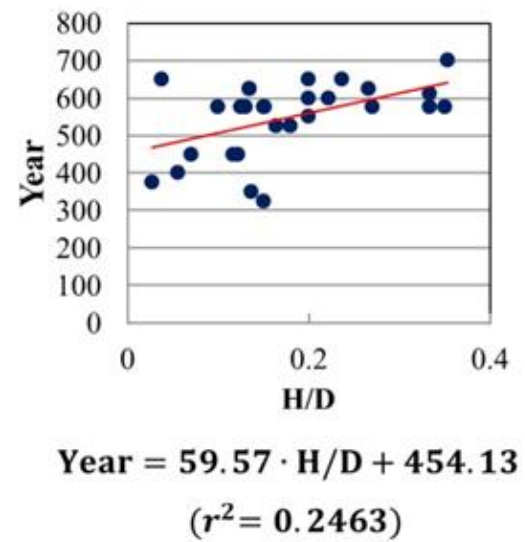

Figure 5. Round tomb age estimate

\subsection{Location optimization of Yamatai}

The estimated locations of Yamatai are two areas, Kyushuu and Kinki (Appendix C), based on the directions and distances in Sanguozhi (Chen, 280). Nobody discussed the family numbers related with population each country. Each country has a family number, which correlated with the river watershed area. Each family has 10 a of a paddy field and the ratio of paddy fields was estimated as 1 to $5 \%$ of each river watershed, $2.5 \%$ on average.

Family number $=\mathrm{a} \cdot$ River watershed area

where a is the ratio of paddy field, 1 to $5 \%$.

Three parameters, the directions, distances and family numbers should be treated evenly for the optimization of the location of Yamatai country. RMS, normalized Root-Mean-Square error, was introduced as the indicator of optimization for Yamatai country location.

$$
\mathrm{RMS}=\sqrt{\left(\frac{D I S a}{D I S S}-1\right)^{2}+\left(\frac{D I R a}{D I R S}-1\right)^{2}+\left(\frac{F A M a}{F A M S}-1\right)^{2}}
$$

where DISa: the actual distance, DISs: the distance in Sanguozhi, DIRa: the actual direction, DIRs: the direction in Sanguozhi, FAMa: the actual family number, and FAMs: the family number in Sanguozhi. The origin of the distances and directions was Seoul in Sanguozhi. Each watershed has the area with the location, which the authors determined by the biggest city each. The area of the watershed was selected the present area each. 


\section{RESULTS}

\subsection{D images}

The dimensions of Akamura tomb in Tagawa were bigger than Hashihaka tomb and smaller than Nintoku (Daisen) in Kinki. The Akamura dimensions were the maximum length: $443 \mathrm{~m}$; the circle diameter: $152 \mathrm{~m}$; the height: $33 \mathrm{~m}$; and the bottom side: $230 \mathrm{~m}$. Hashihaka dimensions were $278 \mathrm{~m}, 150 \mathrm{~m}, 30 \mathrm{~m}$, and $130 \mathrm{~m}$, respectively. Nintoku (Daisen) dimensions were $525 \mathrm{~m}, 286 \mathrm{~m}, 39.8 \mathrm{~m}$, and $347 \mathrm{~m}$.

The fractal dimensions of Akamura tomb were 1.859 for the silhouette for 1.249 for the edge. Those of Hashihaka were 1.846 and 1.227; those of Nintoku (Daisen) were 1.866 and 1.252 (see Figure 1).

The shape factor of Akamura was 2.53. That of Hashihaka was 2.57 while that of Nintoku (Daisen) was 2.21.

As shown above, Akamura tomb was between Hashihaka and Nintoku (Daisen) tombs, and in the same shape as Hashihaka and Nintoku (Daisen) tombs.

\subsection{Dating the ancient tombs}

Ueda(1969) categorized the keyhole tombs into 3types: A type for Hashihaka, B type for Nintoku, and C type for Richu. Akamura tomb is $\mathrm{O}$ type different from three types. Nintoku and Richu were the $16^{\text {th }}$ and $17^{\text {th }}$ emperors. Akamura tomb might be the emperors or the nearest master.

The regression line of keyhole shape tombs was next equation $(\mathrm{N}=38)$.

$$
\text { Year }=296.12 \cdot \mathrm{b} / \mathrm{c}\left(r^{2}=0.3049\right)
$$

where $\mathrm{b}$ is a square size and $\mathrm{c}$ is a total length (see Figs.2,3, and 4).

The regression line of round barrows was next equation $(\mathrm{N}=85)$.

$$
\text { Year }=59.57 \cdot \mathrm{H} / \mathrm{D}+454.13\left(r^{2}=0.2463\right)
$$

where $\mathrm{H}$ is the height of the tomb and $\mathrm{D}$ is the diameter of the tomb (see Figs 2 and 5).

Thus, Akamura keyhole tomb was estimated to be constructed as 399AD, while Onzuka was estimated as 307AD with an error of 30 years.

Therefore, these tombs might be constructed in the late $3^{\text {rd }}$ to the $4^{\text {th }}$ century, which corresponded to the Himiko era, late the $3^{\text {rd }}$ century.

Figure 6 shows these candidates of Himiko's tomb in Tagawa, which spatially distribute through the middle stream of the Onga river.

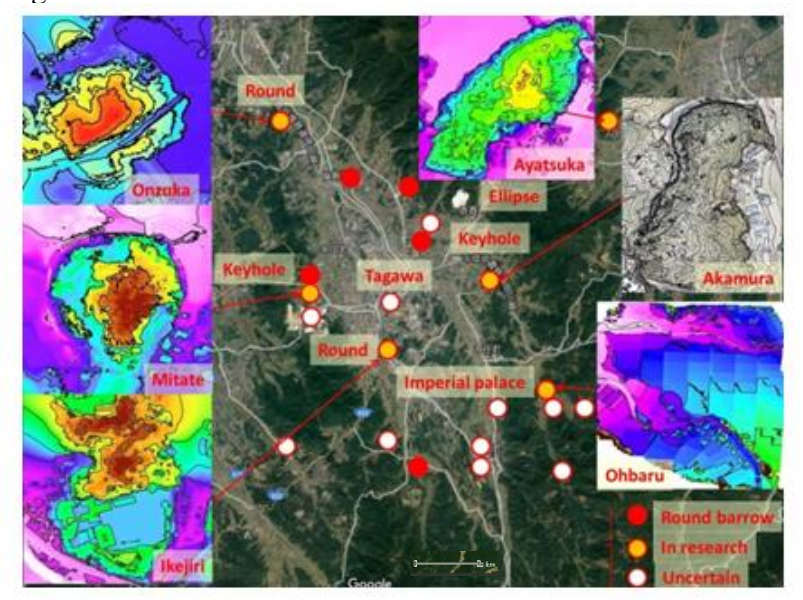

Figure 6. Spatial distribution of tombs in Tagawa

\subsection{Location optimization of Yamatai}

According to a list of rivers, watershed area and sites are shown in Tables 1 and 2. From the watershed areas, family numbers were calculated each. Finally, the results were obtained as Table 3. Yamatai country was estimated as the Chikugo river watershed.

\begin{tabular}{|l|c|c|}
\hline River & Watershed area $\mathrm{km}^{2}$ & Family number \\
\hline Onga & 1026 & 25650 \\
\hline Chikugo & 2860 & 71500 \\
\hline Matsuura & 341 & 8525 \\
\hline Rokkaku & 341 & 8525 \\
\hline Honmyo & 249 & 6225 \\
\hline Kikuchi & 996 & 24900 \\
\hline Sirakawa & 480 & 12000 \\
\hline Midori & 1213 & 30325 \\
\hline Kuma & 1880 & 47000 \\
\hline Yamakuni & 540 & 13500 \\
\hline Ohno & 1465 & 36625 \\
\hline Ohita & 650 & 16250 \\
\hline Gokase & 1820 & 45500 \\
\hline Omaru & 474 & 11850 \\
\hline Ohyodo & 2230 & 55750 \\
\hline Sendai & 1573 & 39325 \\
\hline Kimotsuki & 485 & 12125 \\
\hline Bansho & 464 & 11600 \\
\hline
\end{tabular}

Table 1. List of Kyushu rivers

\begin{tabular}{|l|c|c|}
\hline River & Watershed area $\mathrm{km}^{2}$ & Family number \\
\hline Onga & 1026 & 25650 \\
\hline Chikugo & 2860 & 71500 \\
\hline Matsuura & 341 & 8525 \\
\hline Rokkaku & 341 & 8525 \\
\hline Honmyo & 249 & 6225 \\
\hline Kikuchi & 996 & 24900 \\
\hline Sirakawa & 480 & 12000 \\
\hline Midori & 1213 & 30325 \\
\hline Kuma & 1880 & 47000 \\
\hline Yamakuni & 540 & 13500 \\
\hline Ohno & 1465 & 36625 \\
\hline Ohita & 650 & 16250 \\
\hline Gokase & 1820 & 45500 \\
\hline Omaru & 474 & 11850 \\
\hline Ohyodo & 2230 & 55750 \\
\hline Sendai & 1573 & 39325 \\
\hline Kimotsuki & 485 & 12125 \\
\hline Bansho & 464 & 11600 \\
\hline
\end{tabular}

Table 2. List of Kinki rivers

\begin{tabular}{|l|l|l|l|}
\hline Country & Continuous & Radiated & Kinki \\
\hline Ito & Zuibaiji & Zuibaiji & Zuibaiji \\
\hline $\mathrm{Nu}$ & Hakata & Hakata & Hakata \\
\hline Fumi & Hanazuru & Shika & Shika \\
\hline Toma & Onga & Kuma & Hii \\
\hline Yamatai & Chikugo & Chikugo & Yamato \\
\hline RMS & 0.9241 & 0.6050 & 1.5552 \\
\hline
\end{tabular}

Table 3. List of rivers for countries 


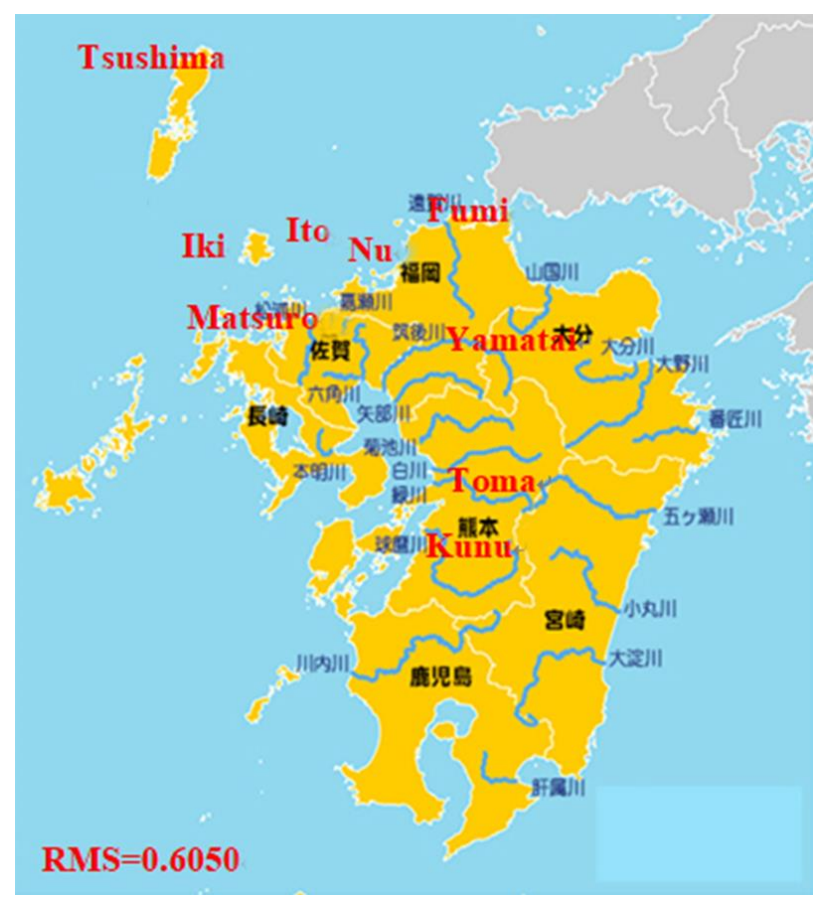

Figure 7. Optimized Yamatai countries (Radiated theory)

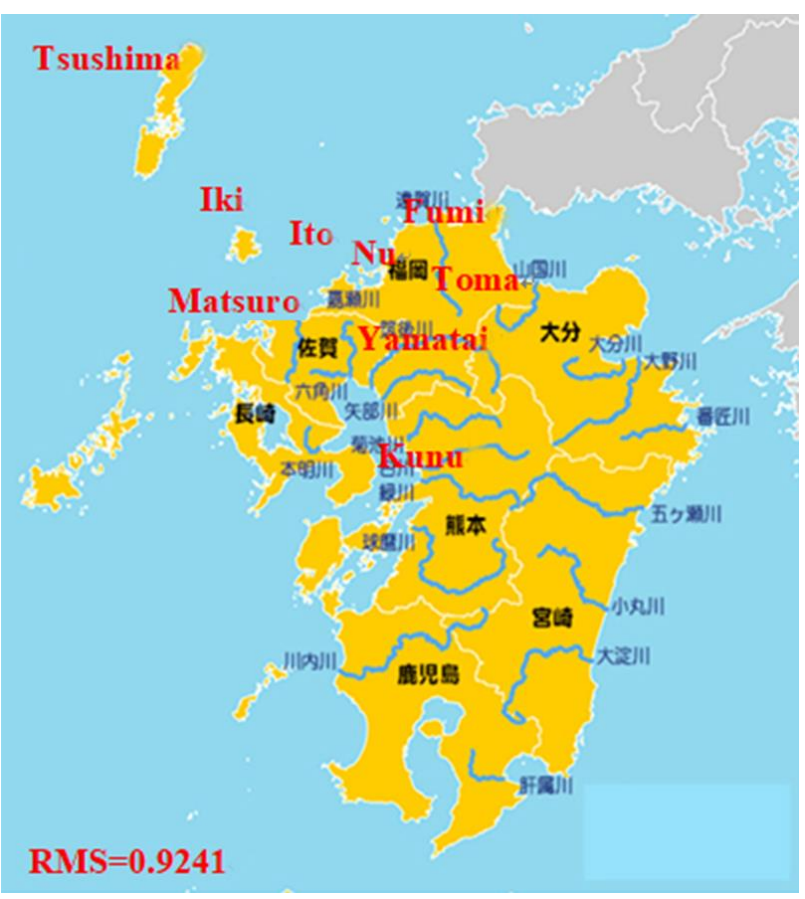

Figure 8. Optimized Yamatai countries (Continuous theory)

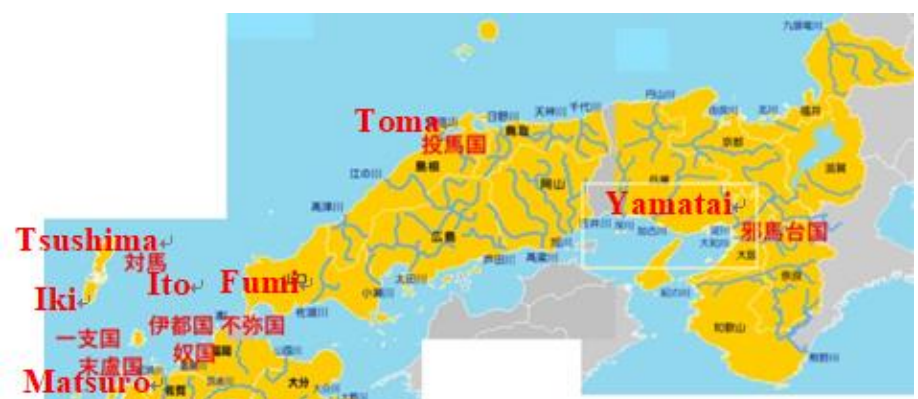

RMS $=1.5552$

Figure 9. Optimized Yamatai countries

(Kinki theory)

\section{DISCUSSION}

\subsection{Two locations of candidates for Yamatai}

Most of historians estimated Yamatai country would exist in Kyushu and Kinki: the former should be the Chikugo river watershed, while the latter should be Yamato river watershed. These location estimates used the direction and distance from Seoul in Korea as described in Sanguozhi. In this paper, the location estimate used the direction, distance and family number with RMS. No historians recognized the family number depended on the river watershed areas. The paddy fields distributed at a certain ratio of the total river watershed areas, 1 to $5 \%$ of the total. Finally, the optimum ratio was $1.94 \%$. Most of the countries in Japan constitute of river watersheds, therefore, the countries in the $3^{\text {rd }}$ century in Yamatai alliance should be also river watersheds each. For more than 100 years, historians could not determine the location of Yamatai between Kyushu and Kinki theories. But, this paper proposed the optimum method to determine the location of Yamatai adding the family numbers as the third parameter and using RMS as an indicator for optimization. As a result, Kyushu theory was accepted in this paper, especially the continuous theory.

\subsection{Himiko's tomb}

Sanguozhi described Himiko's tomb had a diameter of $150 \mathrm{~m}$. This statement suggested Himiko's tomb would be a round tomb. However, most historians and archeologists supported Hashihaka tomb in the Yamato river watershed. This type was a keyhole tomb. In Tagawa many tombs were a round type. Therefore, true Himiko's tomb might be a round type. Onzuka tomb was a round type with a diameter of $150 \mathrm{~m}$, corresponding to Sanguozhi description. Moreover, the construction year was estimated to be $307 \pm 30 \mathrm{AD}$. The location of Yamatai was estimated in the Chikugo river, while the location of Himiko's tomb was estimated in the Onga river. Both two rivers are neighbors. 


\section{CONCLUSIONS}

The authors concluded as next.

(1) Fractal analysis showed almost the same values of fractal dimensions between Akamura tomb and Nintoku Emperor tomb.

(2) Two gigantic tombs in Tagawa were estimated in 307 to 399 year $\mathrm{AD}$ with an error of 30 years, corresponding to Himiko's tomb year. Both tomb diameters were 152 to 264 $\mathrm{m}$, corresponding to Sanguozhi description.

(3) Three parameters in Sanguozhi, the direction, distance, and family number, determined Yamatai country location the Chikugo river watershed, and rejected the Yamato river watershed with the optimization of the location. Therefore, Hashihaka's tomb was also rejected as Himiko's tomb that most historians supported.

(4) The location of Yamatai was estimated in the Chikugo river, while the location of Himiko tomb was estimated in the Onga river, which is a neighbor of the Chikugo river..

In the $3^{\text {rd }}$ century, Yamatai country was a Japanese representative. However, the location of this country and Himiko's tomb was still uncertain. The authors introduced a new parameter from Sanguozhi description to determine the location of Yamatai, which was the Chikugo river watershed. On the other hand, in 2018, a gigantic tomb was discovered in Onga river watershed with a diameter of $150 \mathrm{~m}$, corresponding to Sanguozhi description. Both two locations are very near and the two rivers are neighbors. No historians could determine the locations of Yamatai and Himiko's tomb for more than one hundred years. The optimization by the multivariable analysis with three components could determine the location of Yamatai. However, the archaeological research was not carried out for Akamura keyhole tomb now. Therefore, the validation of the dating should be required for the archaeological research near future.

\section{ACKNOWLEDGEMENTS}

The authors appreciate for Mr. Shinzo Fukunaga and Ms. Takako Amano's cooperation in Akamura research in 2018.

\section{REFERENCES}

Chen, S., 280. Wei history, Sanguozhi.

Ueda, H., 1969. Keyhole tombs, Gakuseisha.

Livi-Bacci, M., 2001. A concise history of world population, Blackwell Pub.

Ogawa, S., Y. Taniguchi, T. Sakurai, S. Fukunaga, 2018. Fractal analysis for the mounded tomb of Himiko, Yamatai, $39^{\text {th }}$ ACRS, Kuala Lumpur.

Taniguchi, Y., S. Ogawa, T. Sakurai, S. Fukunaga, 2018. 3D model by UAV for the mounded tomb of Himiko, $39^{\text {th }}$ ACRS, Kuala Lumpur.

Ogawa, S., Y. Taniguchi, 2019. Age estimate for the mounded tomb of Himiko by shape analysis, $40^{\text {th }}$ ACRS, Daejeon.

Taniguchi, Y., S. Ogawa, 2019. Spatial distribution for the ancient mounded tombs using UAV and digital maps in Fukuoka, $40^{\text {th }}$ ACRS, Daejeon.

Mandelbrot, B., 1983. The Fractal Geometry of Nature, W. H. Freeman and Company, New York. 
APPENDIX A: Photos by UAV

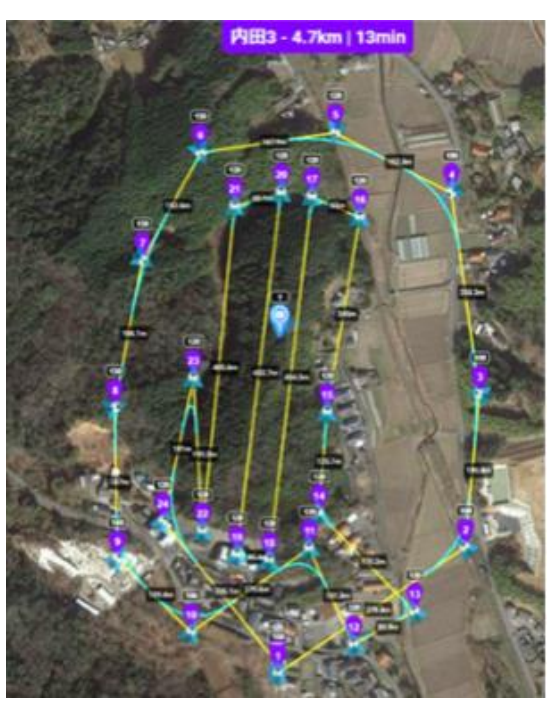

Photo 1. UAV route map for Akamura tomb

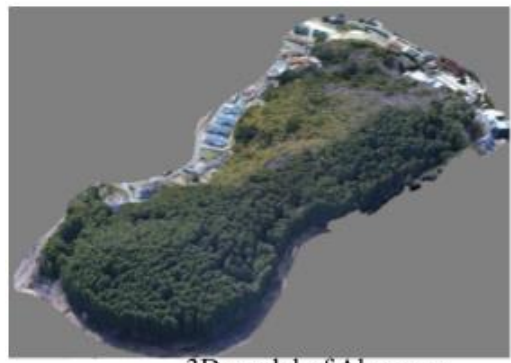

3D model of Akamura

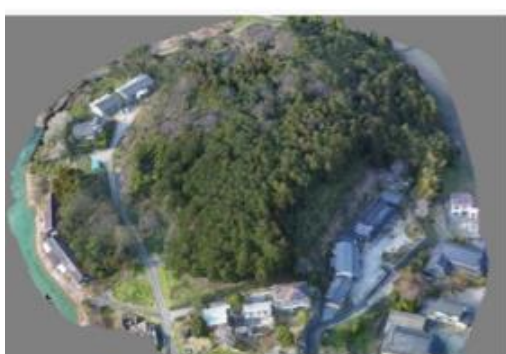

3D model of Mitate.

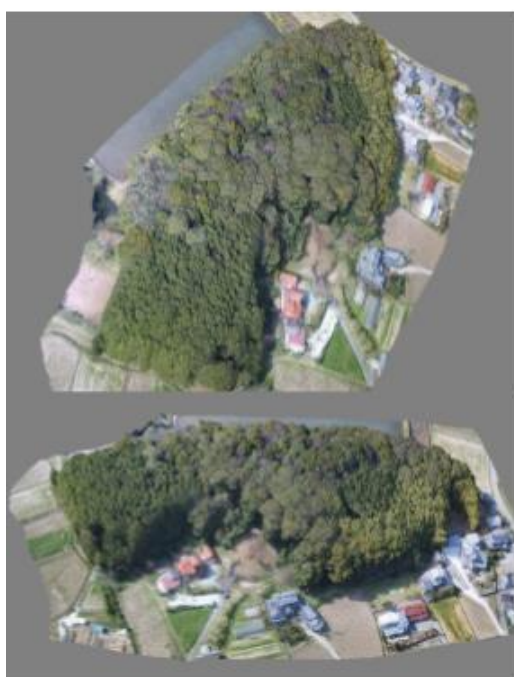

3D model of Ayaduka.
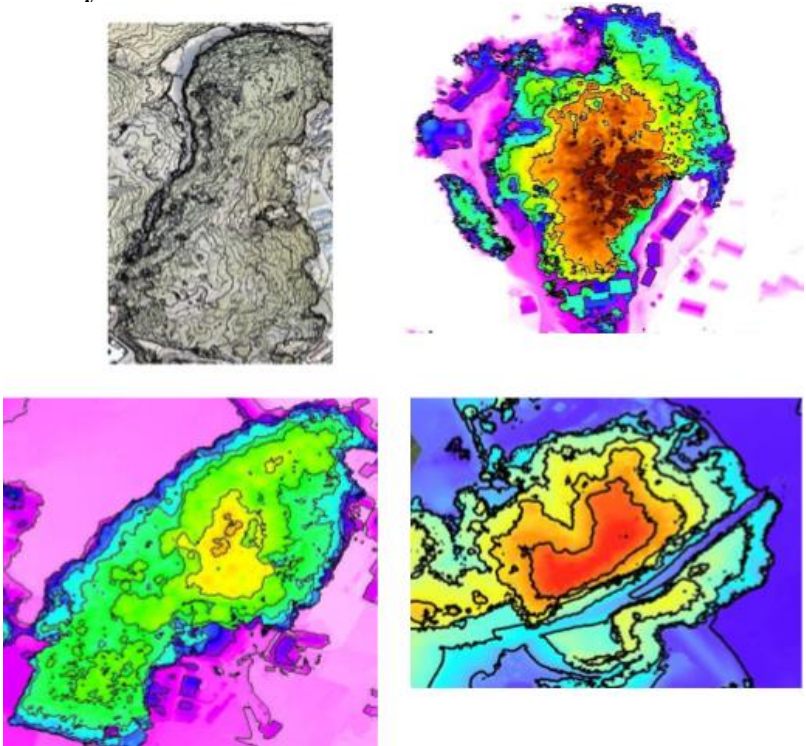

Photo 2. DSM from UAV

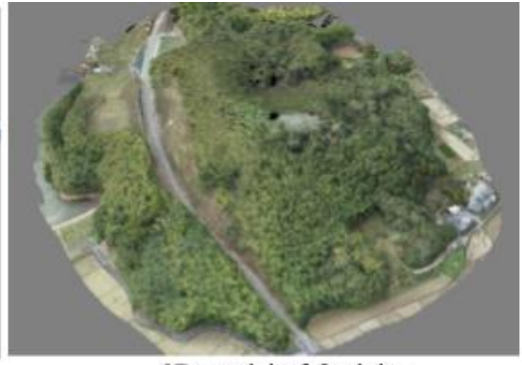

3D model of Onduka

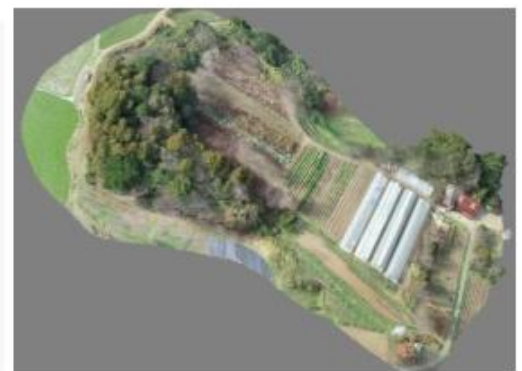

3D model of Miyabaru.

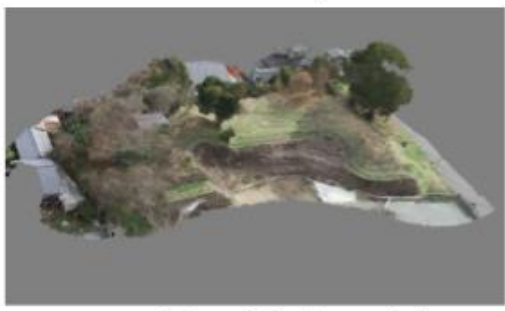

3D model of Syoyaduka.

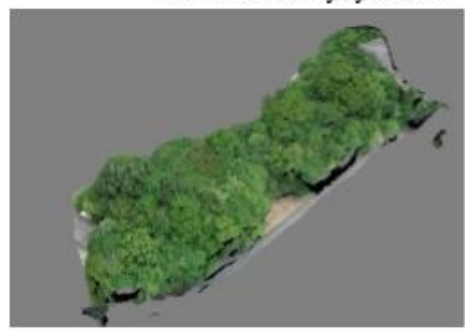

3D model of Sosya

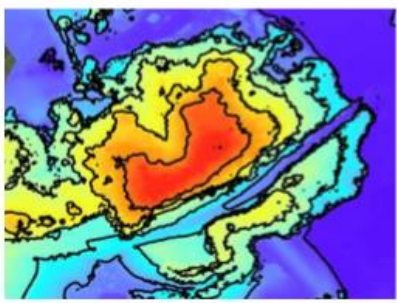

Photo 3. 3D models of six tombs by UAV 


\section{APPENDIX B: Four types of keyhole mounded tombs}

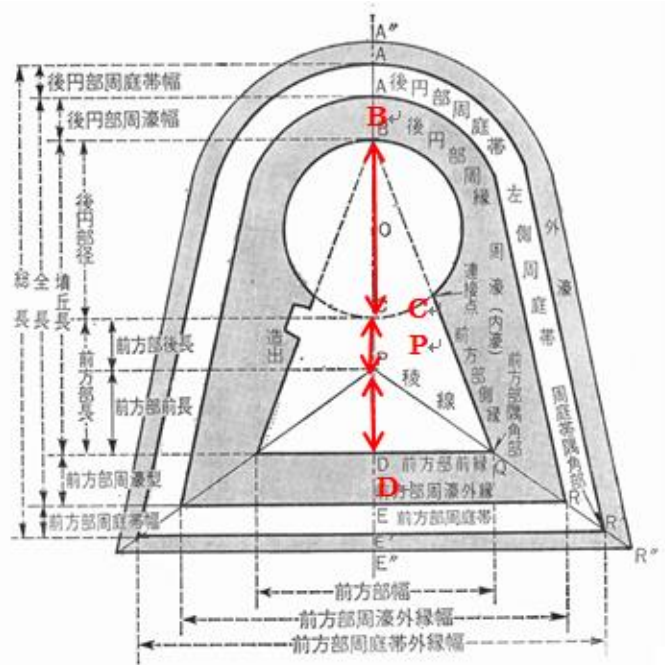

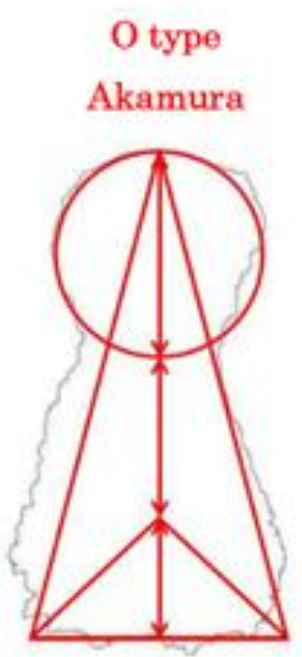

$6: 5: 4$
A type

Hashihaka

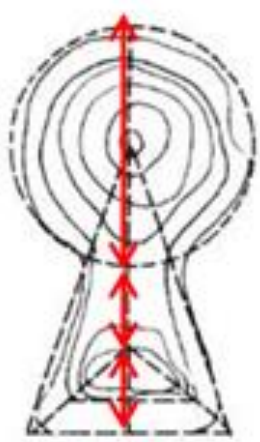

$6: 2: 2$

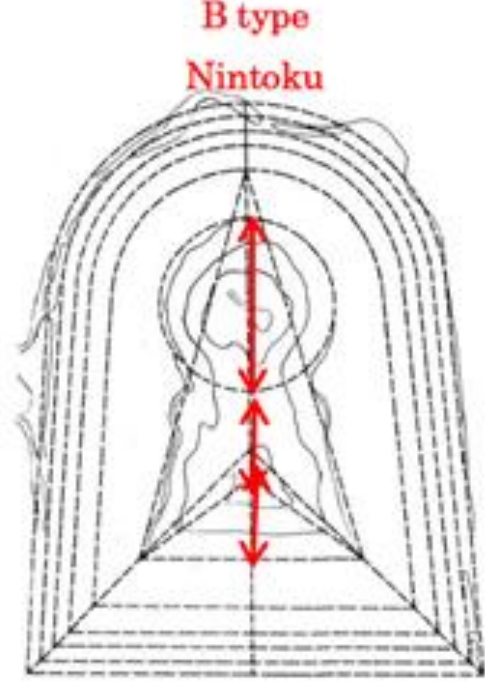

$6: 3: 3$

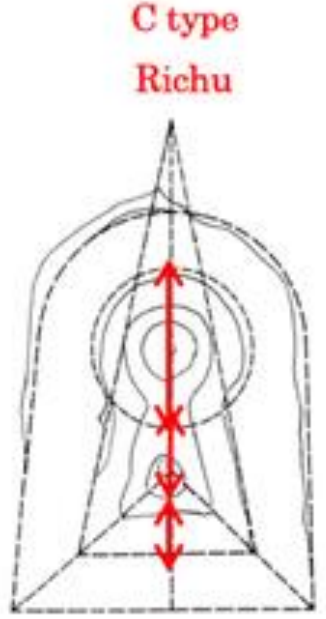

$6: 1.5: 3$

Figure B1. Four types of keyhole mounded tombs by Ueda(1969) classification. Sides BC, CP, and PD are characteristic integers Akamura tomb is O type (left)

\section{APPENDIX C Three theories developed from Sanguozhi}

Yamatai country location was estimated to be Kyushu and Kinki areas. The former was developed to Continuous and Radiated theory.
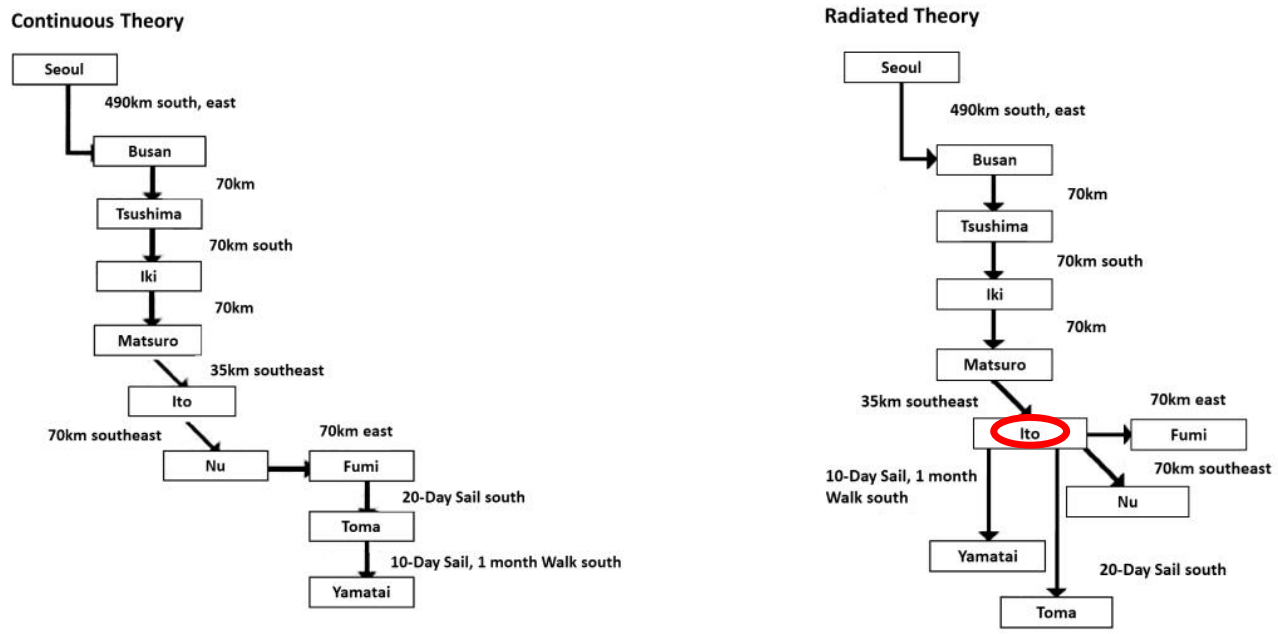


\section{Kinki Theory}

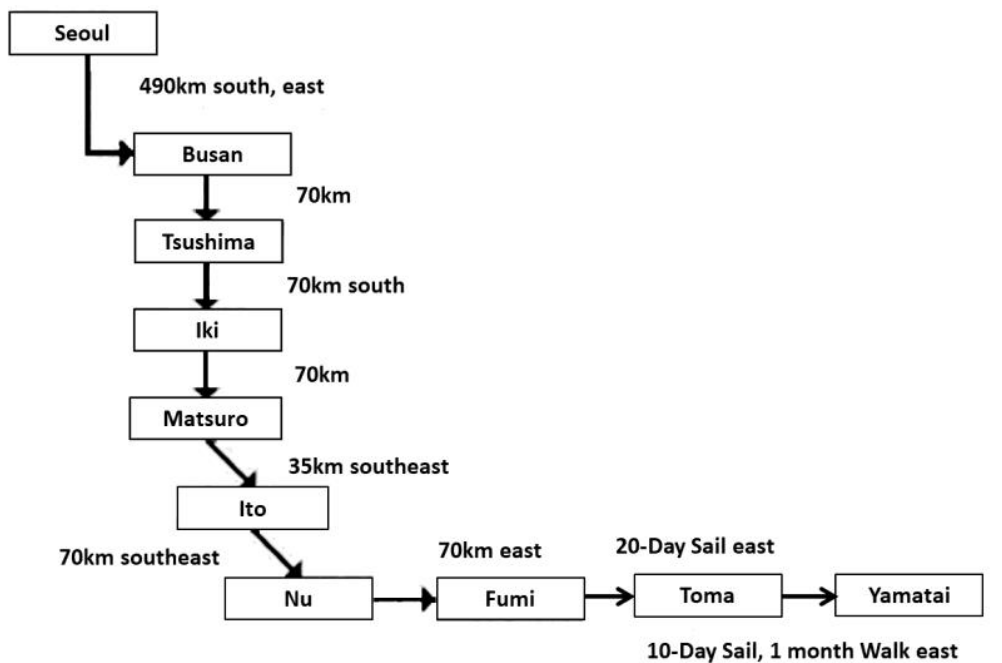

Figure C1. Three theories developed from Sanguozhi: Continuous theory (left upper), Radiated Theory (right upper), Kinki theory. Japanese historians had discussed the location of Yamatai for the past more than 100 years, but nobody solved it. They proposed three theories as shown in Figure C1. All historians ignored a parameter, family numbers, which were described in Sanguozhi. The authors introduced this parameter into multivariate analysis with normalized root-square-mean errors, RMS for three theories. Continuous Theory determined the locations of Yamatai countries in the same order as described in Sanguozhi, while Radiated Theory changed Ito country as the center of Yamatai adjusting real locations of Kyushu. However, Kinki Theory ignored the directions of the countries described in Sanguozhi adjusting real locations of Kinki. Kyushu is a big island and Kinki is the western part of Japan. The relationship between Yamatai and Japanese emperors was still uncertain. 